\title{
DYNAMICS AND GROWTH OF TELECOM SECTOR IN RURAL INDIA: A TECHNO-ECONOMIC ANALYSIS
}

\author{
Dr Jasmeet Kaur \\ Prof. in Economics, \\ Faculty Head- International Cell \\ Symbiosis International University, \\ Pune, India
}

\begin{abstract}
The current rural tele-density, both wireless and wire line combined, is $43.13 \%$ as per TRAI press release no 13/2014 as compared to the urban tele-density of 145.39. Since the urban market is saturated, there is an immense scope of growth for the telecom operators in rural India. Also there are social factors, pertaining to rural India, which affect their decision making one of which includes subscription to telecom services. The study intends to analyse the social factors in coherence with the growth of telecom in rural India to understand and establish interdependencies between the factors.

The objective of this paper is to study and analyse the correlation between various techno-economic factors, which have been shortlisted as education and agriculture, with respect to telecommunications and propose a socio-economic model for the telecom operators which would help them understand the factors influencing the telecom service subscription and hence tap the rural market efficiently.

The important aspect related to this is the level of literacy achieved in rural India and the mobile penetration rates in villages. These two factors are co-related as nowadays the ICT intervention is coming through mobile applications which are making the rural population aware of their rights and are giving them chance to connect with the related beneficial information. The other aspect has been the household expenditure of rural India, with the increasing income the spending behaviour is bound to increase and this spurs the economic cycle. As the economic activities increases the competitiveness emerges which again raises its heads towards efficiency. This efficiency is again achieved with the ICT services intervening at every step of agriculture supply chain/value chain and thereby making profitable proposition for the farmer community.
\end{abstract}

\section{INTRODUCTION}

The current paper analyses the impact of telecom on income level and education of rural people. We would also study the impact of telecom in agricultural development and Technological enhancement in these areas. As proposing a Socio-Economic Model paper considered Income level as economic factor and education as social factor. Per Capita income has increased $17 \%$ in case of rural India and $15 \%$ in case of urban India. In this model we have consider many factors like Education , Technology, Agriculture, Healthcare etc. and we finalised three factors on which the model will be based which are Education, Technology and Agriculture. 
Rural Telecommunication in India:

Tele is Greek word meaning distance and communication is started from the Latin word Communise which means common. Communication is the process by which message are transfer from source to receiver. Telecommunication is defined as the sharing the feeling to those people who are neared or far away from us. Telecommunication is the transmission of messages, over significant distances, for the purpose of communication.

Process of Telecommunication

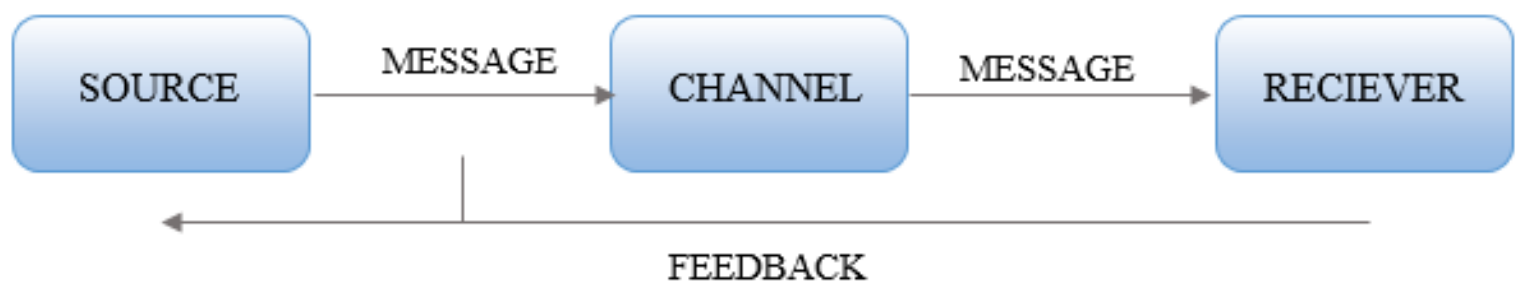

Figl: Process of Communication

Present Status of the Telecommunication

Sector:

Indian telecom network is second largest

Twelfth Plan Targets for the in the world after China. The country has 933 million telephone connections, including 895.51 million wireless telephone connections. Overall tele-density in the country is $75.34 \%$. Urban teledensity is $149.55 \%$, whereas rural teledensity is $43.90 \%$. The share of wireless telephones in total telephones is $96.56 \%$. The share of private sector in total telephones is $85.51 \%$. Number of Telecommunication Sector:

- Provision of 1200 million connections by 2017.

- Mobile access to all villages and increase rural tele-density to 70 per cent by 2017 .

- Broadband connection of 175 million by 2017 .

- Commissioning of National Optical Fiber Network (NOFN)

Broadband connections is 14.98 million. 
- Make available additional $300 \mathrm{MHz}$ of spectrum for IMT services

- Making India a hub for telecom equipment manufacturing by incentivising domestic manufacturers with thrust on IPR, product development and commercialisation.

- Provide preferential market access for indigenously manufactured products.

- To increase domestic manufactured products in telecom network to the extent of 60 per cent with value addition of 45 per cent by 2017 .

- Adoption of green policy in Telecom and incentivise use of renewable energy sources.

Recent Policy Initiatives in Telecom Sector:

- All villages shall receive telecom facilities.

- National Long Distance Service (NLD): open for unrestricted entry.
- The International Long Distance Services (ILDS): open to competition.

- The basic services: open to competition. 4th cellular operator (over existing 3, 1 each in 4 metros $\& 13$ circles) permitted.

- Policies allowing private participation in several new services: Global Mobile Personal Communication by Satellite (GMPCS), digital Public Mobile Radio Trunked Service (PMRTS) and voice Mail/Audio text/Unified messaging WLL for telephone connections in urban, semi-urban and rural areas.

- Disinvestment of 2 public sector telecom undertakings, VSNL and HTL.

- Steps to fulfil Universal Service Obligation (USO) funding and administration.

- A decision to permit Community Phone Service for each panchayat. 
- Multiple Fixed Service Providers (FSPs) licensing guidelines announced

- Internet Service Providers (ISPs) allowed to set up International Internet Gateways \& both Satellite \& landing stations for submarine optical fiber cables.

- Two categories of infrastructure providers have been allowed to provide end-to-end Bandwidth and dark fiber, right of way, towers and duct space.

- Guidelines by the Govt. to open up Internet Telephony.

Mobile Technology and

Telecommunication:

Mobile technology refers to technology that is portable. In this since of the term mobile technology includes: mobile phones and smart phones end phones with more advanced capacities, laptop computer and global positioning system devices and so on Telecommunication technology defined in terms technical features and standards of services delivered to the consumers

Telecom Service Providers:

In the public sector, the operators are:

i. Mahanagar Telephone Nigam Limited (M.T.N.L.) for cities of Bombay \& Delhi

ii. Bharat Sanchar Nigam Limited (B.S.N.L.) for the rest of India: BSNL has managed to honour obligation by providing connectivity to $90 \%$ of the rural population

In the private sector, the operators are:

i. Bharti Airtel: It is the largest operator and would extend its coverage to more than 4,000 towns and adjoining villages.

ii. Reliance Communications: It currently provides services in 4,300 towns and claims to have connected all the adjoining villages in these towns.

iii. Tata Tele Services Limited (TTSL): It currently claims to have over $8 \%$ of the rural customer base. Provides Tata 
Indicom, Tata DoCoMo, Virgin (GSM) \& Virgin (CDMA).

iv. Idea Cellular, Vodafone Essar, Aircel . Uninor, HFCL, Infotel and others like Spice Telecom, Videocon Mobile Service, MTS India, Loop Mobile (BPL formerly), Ping Mobile, S Tel and Etisalat DB.

In rural areas telecommunication provides awareness, information related to agriculture, animal husbandry, horticulture as well as education. Rural development is only possible if the updated information is given to the rural people. The Indian telecom network, 556.92 million telephone connections are in urban areas and 338.59 million are in rural areas. Urban tele density is $149.55 \%$, whereas rural teledensity is $43.90 \%$. The change is more visible in countries like India for the geographical penetration and adoptability of the mobile phones is very high compared to other Information and Communication technology and services. The wide penetration of mobile phones in India is fundamentally because the major constraints for the low rural tele-density have been lack of investible resources, non-availability of appropriate technology combined with difficult geographical terrain and continental size of the country. The most common rural connectivity challenge in India can be summarized as:

- Fixed-line connections

- Fixed wireless terminals

- Subsidy provision

- Infrastructure

This paper studies the correlation and interdependence between the factors like education, agriculture and technology and overall rural tele density to help Telco's to focus on the key areas and increase their penetration in rural areas.

\section{LITERATURE REVIEW}

At the time of independence India had only 84000 fixed line for its 350 million population (Rao \& Pattnaik, 2006). India's tele-density in 1948 was below $0.5 \%$. Telecom was the preserve of public sector enterprises only although the five year plans gave importance to the development of telecom sector. But even though after 
the emphasis on developing telecom sector the tele-density in 1998 was below $2 \%$. After the telecom regulation of 1997 the sector grew 12.5 times over the preregulation period (Baijal \& Jain, 2007). The rural consumer can never pay $\$ 50$ per month as in the case of London, Tokyo etc. neither they can pay $\$ 7-10$ per month as in case of Mumbai and Delhi but they can surely pay upto $\$ 2$ per month and their capacity to pay is increasing with the increase in the communications (VNL Report, 2009). The rural telecom revolution in India started in 1988 and increased the telephone facility to 3 , 00,000 villages in 1998 from 27316 villages (Rao \& Pattnaik, 2006).

According to TRAI Report, 2005, there are three ways in which the communication technologies affect the poverty - providing a platform to better deliver the public services, increase the efficiency of the economy, and creates new sources of income. FAO report, 2009, attributes mobile telephony as the bridge between the individuals and institutions which makes the sharing of information and knowledge easier and more effective. The triggers for the massive increase in mobile penetration have been many. Factors such as price, income and tastes have all been important determinants.

The initiatives taken currently focuses on infrastructure development and tries to extend the information technology services from the centre to the periphery. ICT can benefit the rural economies in three broad areas - Social Production, social consumption, and social services. Application of ICT in rural development sector either directly or indirectly is known as "Rural Informatics". Rural informatics can be used for sustainable development only if the ICT interventions are able to adapt to local needs and re-adjust itself according to the available information (Chitla, 2012).

ICT provides the orifice for the transmission and knowledge to an individual person to enlarge the spectrum of choices for social and economic empowerment. The need for the hour is a successful ICT application in e- 
Governance as a one stop solution for the rural population. Different e-Governance applications deployed in rural areas as the part of National e-Governance plan (NEGP) have actually demonstrated the improved government services. There are schemes like Mahatma Gandhi national rural employment guarantee act (MGNREGA), e-office, online income tax etc. has improved the delivery of services in respective areas and thus contributing to the economic development. The term eGovernance implies the usage of new ICTs by the government in its full range of functions. Thus it is the application of ICT which describes the e-Governance. It has been done by government of India In the form of deploying Common service centers (CSCs) kiosks in every village to fulfil the needs of a common man.

According to the India Year Book 2014, published by Ministry of Information \& Broadcasting, Government of India, establishment of 100,000 common service centres have been approved in 600,000 villages of India. The common service centres (CSCs) scheme envisions these kiosks as the front and the delivery points for government, private sector and social sector services to the rural population of India in an integrated manner. The National e-Governance project is considered as the novel project undertaken by the government of India, it has been partially funded by the World Bank to the tune of US \$150 million. Governments in many parts of the world are making huge investments in ICT to improve the governing process. The National eGovernance Plan does not only gives platform to apply ICT in villages but also envisions to connect District administration in the backend so that efficiency is increased in the delivery of services and the unnecessary commutation of villagers to the district headquarters for availing government services is saved.

Many authors have a different view altogether regarding the rural development. There is no definite and precise definition of rural development, but it definitely means empowering the 
voiceless and reduce their exploitation (Ghosh, 2011). According to him the major driving force behind the rural development is communication. $\mathrm{He}$ attributes ICT as the application of innovative ways of facilitating information and communications in the rural domain. The advancement of ICT in rural areas can be leveraged to provide critical and useful information to the farmers who are already distressed with the truant monsoon. He has given following points as the advantages of ICT in rural domain -

- Efficient delivery of health and allied services

- Gives access to quality education and thus improving literacy rate

- Value based inputs to the farmers to improve their productivity

- Providing entertainment at the door step of rural populace

- Delivering relevant news in rural areas

ICT can be leveraged by rural population so as to get connected with the local, regional and national economy and access markets, get employment opportunities and avail banking and other financial services. ICT can also be seen as the instrument of awareness and a tool for giving feedback and thus can be portrayed as voice of voiceless. This will give the rural population a sense of inclusion with the nation's socio-political life (Gulati, 2012). According to Gulati, ICT should not only give affordable information but also deliver relevant and usable content as without that the ICT services will not be productive enough to give rural development a boost. She asserts that both content and capacity building integral and necessary parts for ICTs to provide their promised impact in rural development.

Some reports regarding the penetration of ICTs in rural areas talk specifically about the penetration of mobile telephony. FAO report 2009, states various benefits of mobile telephony which can be enumerated as below -

- Bridges the gap between the urban and rural populace and connects 
them to global communication channel

- It extends and helps the community radio to reach wider sphere of population

- It makes the local content available to everyone

- It makes the rural services more efficient and cost-effective

Nowadays a massive attention is being given to poverty reduction drive in India. According to World Bank 2014 analysis report India has $20.6 \%$ of world's poorest population. At any point of time if ICT services are put in place to reduce poverty then it should have tailored services and applications developed for this purpose. ICT would be able to achieve its objective of reducing poverty depending upon below three criteria:

- Local poverty reduction measures and ICT applications should be complementary to each other

- ICT services should respond to local needs
- It should involve stakeholders in application development

The actual goal of using ICT with marginalised groups is to overcome the digital divide and enforce the process of social inclusion (Chitla, 2012). Households from marginalised communities face extreme levels of exclusion from basic social services (Acharya, 2009). ICT initiatives like CSCs scheme attempts to overcome this barrier. Not only marginalised groups but also women are able to find employment opportunities due to the ICT applications reaching far remote areas of India.

Enhanced deployment of ICT eliminates social hierarchies in rural area. However Sreekumar, 2007, argues that ICTs are not able to achieve what they were projected to do so as they are not gender sensitive. He asserts that the participation of women and underprivileged is abysmally low and thus the objective of social inclusion is not achieved. 
Some authors try to look differently on the aspects of implementation of ICT in rural areas. They have tried to bring forth the barriers in the ICT implementation. Educating and providing information to nearly 7 lakh villages of India is a daunting task which is next to impossible moreover it makes the whole idea financially unviable. There are other major hurdles apart from finance like power availability, low ICT literacy, and poor infrastructure of ICT etc. Some farmers believe that if they adopt ICT techniques it will require them to forget their traditional methods and this makes them averse to adopting the new techniques. Therefore before making a huge investment in ICT in rural areas there is a need to change the mind-set and attitude of farmers (Chitra \& Shankaraiah, 2012).

Some authors are of the belief that the dissemination of information to the farmers should be a stage wise process and not one final strike methodology. The stage wise process creates confidence, trust and belief on the technical intervention to the farmer. This procedure will also help farmer to internalise the cost sharing aspect of information sharing and other advisory services. Farmers will not agree to cost sharing if they are not shown the usefulness of the information being shared. Also if an ICT initiative is successful in one state it doesn't mean that the same can be implemented in every state, it again needs to be customised to make it implementable in other regions therefore the commercial deployment requires dynamic business model and flexible ICT technology in order to make it sustainable in long run. The adoption of technology in most cases is based on firstly kiosks and then later on mobile phones. The latest trends in education, government services, health sector, banking etc. are the innovative applications created on mobile phone platforms. This is compounded by the fact of high mobile penetration in the rural part of the country. This scenario is the best example of knowledge based economy which has the typical characteristic of creation of new ideas for the benefit of the stakeholders and marks 
the definite shift from the traditional production of goods. Having mobile only does not help farmer economically but when this mobile is linked with useful information and tools then it really can make a difference (Rao, 2013).

Over the last decade India has emerged as the preferred destination for IT outsourcing services. Much of the impact can be seen as finance, insurance, transport etc. have adopted IT in big way. However agriculture is still lagging behind. The miniscule efforts made in this direction are not enough. Practically speaking there is not a single area in agriculture where IT services cannot be leveraged (Prasad \& Shekhar, 2013). Prasad \& Shekhar in their book titled "Sixty-five years of Indian Economy" have asserted that introduction of IT services in agriculture depends on the main functionaries who are involved in Indian agriculture. Following are the main functionaries:

- Farmers

- Industries providing inputs to agriculture
- Industries dealing with agricultural output (Forward Chain)

- Central and State governments

- NGOs working in this sector

- Agricultural Universities and research centres

In spite of the best concerted efforts by government and making huge expenditures in this sector the traditional apparatus has failed to deliver the output satisfactorily. This brings the role of IT services much more pertinently. Obviously the cost of IT equipment is out of the budget of individual farmer therefore this requires the institutional effort to provide the IT services to farmers. There is already an agricultural informatics division in NIC which helps in bringing IT-led development in this field in ministry of agriculture.

Some authors are of the opinion that content to be disseminated to the farmers is equally important as the ICT infrastructure is. For small and marginal farmers, generation and transmission of 
quality information is of utmost importance. ICTs make storage and retrieval of agricultural information easy, it also helps in disseminating already established procedures and practices to common farmer (Chapman \& Slaymaker, 2002). It is known that ICT intervention distributes relevant information to farmers also the customisability of information for a particular region makes it more useful for the farmer community. But this customisability is certainly not every time successful as the content which is pushed is not always demanded by the farmer; hence the flexibility in ICT intervention is required at this step (Ballantyne, 2002). The information disseminated should be based more on demand pull model. This flexibility will only come with lot of intelligence and opens an entirely new domain of technology. However at the present level of technology penetration in rural areas of the country there is very low level of intelligence used. To make this intelligence working there is a requirement for huge storage and other analytical tools which can be placed only when there is sufficient commercial viability. Cloud service providers haven't yet entered the agricultural arena in the country. Moreover it requires to answer many unanswered questions like what business model do the cloud providers have to follow, will farmers agree to cost sharing model, will farmers understand the meaning of cloud services and would they be able to trust on cloud providers? These questions if not answered may scuttle the whole idea of introducing meaningful technology in agricultural fields.

There is ample opportunity to strengthen the growth of agriculture in India, if there is value-addition done through agro processing. Agro processing is being at an abysmal level in the country. There are many evidences now to show that the consumption pattern of food commodities are making a transition towards high-value commodities like fruits, vegetables, milk and eggs. This transition has been attributed due to the increase in the per capita income of the people, urbanization, changes in lifestyles of people etc. also the awareness of health aspects. If this 
information is shared on real-time basis with the farmer and the supply chain then it would have given opportunity for the farmer to make informed decisions and thus helping in increasing his income (Pervez, 2014).

Consumer class of India is growing rapidly and they are getting attracted towards more and more fresh, palatable, nutritious and safe food. Moreover the consumer class not that much averse to the prices of these commodities and are now placing health first in their decision making criteria therefore there is an utmost need of introducing technology in the agricultural back-end so as to cater to the dynamic demand of the consumer. Also when the agricultural sector will get connected to the ICT it will be easy for the farmers and traders to get quality certificates for their products which again will meet the consumer demand and will be required in the market thereby considerably appreciating the income of the farmer. Investment by private sector organisations is very low due to the high presence of government regulations in this sector. Procurement, Storage, warehousing and marketing all the verticals of agriculture are highly regulated. There are also laws which are restricting contract farming and land leasing. However, due to the change in the global food market some of the states have initiated the amendments in their APMC (Agriculture Produce marketing Committee) Acts therefore paving way for the private investment.

In order to leverage the varied advantages of the Information services in the agriculture sector there is a need to strengthen the vertical relationships between various stages of production of agriculture commodities and this includes the integration of agro-processing industries with the agri-supply chain. This integration however has been only seen in some high value commodities like poultry, milk, fruits and vegetables. This shows that the commercial viability is the major cause for this. Therefore there is required an institutional measure like public-private partnership to make this integration penetrate the low value commodities and 
to come up with some kind of sustainable solution. However in the initial phase government has to absorb some losses and let the wheel rolling until it becomes commercial viable. This moratorium period can also bring some doubtful farmers in the cycle that would be initially apprehensive with the whole idea.

A general flowchart for the Indian agriculture supply chain can be shown as below:

The above flowchart gives the outline of the "Mandi" route which the agriculture produce follows before it is sold to the end consumer. No doubt, a cumbersome process with lot of manual intervention. This process can be both reduced and integrated with the help of IT.

Supply chain management and agricultural business are integral part of agricultural marketing system. Efficient supply chain and business models are necessary for creating efficient agricultural market which delivers agricultural produce from the farmer to the consumer in the most efficient way. While output and productivity are supply side factors, markets provide an intermediate link between producers and final demand by consumers. Efficiently functioning markets add to welfare of producers as well as consumers. Efficient agricultural markets can also be a potent tool for poverty reduction.

Fig 2: General Flowchart for the Indian Agriculture Supply Chain

Keeping the present state of affairs in mind the supply chain of agriculture business in India along with the business models working in this sector are critically inefficient and are not made to face the dynamics of the market forces which are emerging with the growing ICT field. The new technologies are changing the market rules every day along with that the needs and demand of the consumer are changing this has to be kept in mind while any business model is thought of before implementing. Therefore it is of dire necessity that the business models which are to be brought in this field should be 
flexible enough so that they can sustain the fluctuating demand of the consumer. These business models should have the backing of appropriate investments which can only be possible if there is transparent and less complex regulatory environment in this sector.

Use of ICT solutions will make the movement of agriculture produce easy and uninterrupted. The current fragmented marketing system and the lack of critical infrastructure are some of the serious constraints which are having toll on the productivity if this sector. This calls for immediate intervention from the government in the form of deploying the ICT infrastructure and installing applications in order to leverage this infrastructure.

In a nutshell it can be concluded that there are varied benefits if the ICT intervention is implemented in the agriculture sector within the country. There are also evidences of the ongoing projects of ICT which are helping the farmer community in their own way but the need of the hour is to have integrated solution to this aspect so that the key stakeholders in this field are benefited which in turn will help in improving their socio- economic condition. The important aspect related to this is the level of literacy achieved in rural India and the mobile penetration rates in villages. These two factors are co-related as nowadays the ICT intervention is coming through mobile applications which are making the rural population aware of their rights and are giving them chance to connect with the related beneficial information. The other aspect has been the household expenditure of rural India, with the increasing income the spending behaviour is bound to increase and this spurs the economic cycle. As the economic activities increases the competitiveness emerges which again raises its heads towards efficiency. This efficiency is again achieved with the ICT services intervening at every step of agriculture supply chain/ value chain and thereby making profitable proposition for the farmer community. 


\section{RESEARCH METHODOLOGY}

To develop a socio-economic model for rural India, it is necessary to study various parameters intrinsic to the pastoral populace and establish correlation between them, positive or negative in order to develop a germane model. This model aims to develop a connection between the basic social parameters, relevant to rural India, and the telecommunications industry and establish an equation justifying the same.

To achieve this, various documents like white papers, research papers, government data and reports, etc. were studied to create a base for the research.

The research methodology is pictorially represented as follows:

\section{PURPOSE - Objective Setting}

\section{PREPARE - Literature Review}

ANALYZE - Establish Pattern

\section{SUBSTANTIATE - Data Exploration}

\section{IMPLEMENT - Create Model}

Fig 3: Research Methodology

\section{PURPOSE - Objective Setting:}


- To develop a socio-economic model for the rural market identified a few factors like health, agriculture, education, technology, etc. Out of these, identified three important parameters where ICT can drive the development and help uplift the standards of rural markets.

- These are:

i. Agriculture

ii. Education, and

iii. Technology

- These are, also, the major focus areas for all activities in the rural areas. These factors are inter-related, directly or inversely, with each other.

- Objective is "To determine a bow and arrow strategy for ICT development in Rural India”.

\section{PREPARE - Literature Review:}

- Studied various government websites like MoHRD (Ministry of Human Resource and Development), DoT
(Department of

Telecommunications), TRAI (Telecom Regulatory Authority of India), NSSO (National Sample Survey Organisation), PCI (Planning Commission of India), etc. to find out the factors driving and affecting the aforementioned parameters in concurrence to the objective stated above.

- This would help us better analyse the correlation, if any, between these factors and establish a pattern between the parameters.

\section{ANALYZE - Establish Pattern:}

- Based on the information received in the above step, we have established a relationship and pattern between them.

- This research is a study project to verify and establish, if any, significant relationship and correlation between the 
parameters which can be of future value.

\section{SUBSTANTIATE - Data}

\section{Exploration:}

- Once the relationship has been established and a pattern is identified between the three parameters, found quantitative data to substantiate the above relationship.

- Considered secondary data of past seven years i.e. from 2007 to 2013 as per financial year (April to March) for analysis. Data was fetched from various government sites mentioned above.

- Imperative parameters for these three were considered to collect the data. These were:

i. Telecommunication considered Total Rural Subscriber Base, specifically for rural India, which includes subscriber base for both wireless and wire line. ii. Education - considered the Total Rural Literacy Rate of rural India and the Literate Population of rural India iii. Agricultural - considered HFCE (Household final consumption expenditure)

- Quantitative data will help to attest the pattern which has been established.

- Also it helped in analysing the trend of these three sectors, especially in coherence with telecom, which in turn was used to create the final model.

\section{IMPLEMENT - Create Model:}

- On completion of data gathering, mining and analysing; created a model useful for the telecom operators, substantiated by the data collected in the previous step, to leverage the social factors of rural India to increase their rural coverage.

- To build a model Eviews and SPSS are used. 
- The data collected was fed into the software to obtain statistical relation between these parameters.

- Granger test and stochastic autoregressive modelling was used to determine the correlation between the parameters, establish a pattern of the data and develop a model based on the parameters.

Throwing some light on explaining in brief the above mentioned tools used to create the model.

\section{Correlogram:}

A Correlogram is a tool used for time series analysis. This tool helps analyse the correlation between variables over a period of time. It is also known as AutoCorrelation plot. Correlogram is a common tool used to test the randomness in a data-set. If the auto-correlation nearzero, the data values are said to be random. However, if the auto-correlation is significantly non-zero, the values are nonrandom.
The Granger Causality Test is a statistical concept based on prediction. It is used for establishing whether one time series is can be used to forecast another time series. A time series $\mathrm{X}$ is said to Granger-cause $\mathrm{Y}$ if it can be shown, usually through a series of t-tests and F-tests. In this test, the causality relationship based on two principles:

1. The cause happens prior to its effect.

2. The cause has unique information about the future values of its effect.

Based on the results of the above two tools, a stochastic autoregressive model is prepared.

\section{DATA ANALYSIS AND FINDINGS}

The data of the three aforementioned factors are as follows. This data has been collected from various authentic sources for all three factors. All the data has been collected for a period of seven years from 2007 to 2013.

\section{Data Findings:}

\section{Literacy:}

\section{Granger Causality Test:}


The Literate population specifically of rural India has been found. Based on the Census population of 2001 and 2011 and the literate population of 2001 and 2011 were taken. In order to have yearly rural literate population, we divided the difference of the two figures in ten equal parts. And hence, we came up with the following data:

\begin{tabular}{|l|l|}
\hline Year & $\begin{array}{l}\text { Literate Population } \\
\text { (in million) }\end{array}$ \\
\hline 2007 & 440.56 \\
\hline 2008 & 453.68 \\
\hline 2009 & 466.79 \\
\hline 2010 & 479.91 \\
\hline 2011 & 493.02 \\
\hline 2012 & 506.14 \\
\hline 2013 & 519.25 \\
\hline
\end{tabular}

Table1. Rural Literate Population, India

\section{HFCE (Household Final Consumption Expenditure):}

The household final consumption expenditure represents the spending of an individual or resident household on consumable goods and services. HFCE, as defined by the World Bank, is the market value of all goods and services, including durable products (such as cars, washing machines, and home computers), purchased by households. It excludes purchases of dwellings but includes imputed rent for owner-occupied dwellings. It also includes payments and fees to governments to obtain permits and licenses. We have taken this data specific to the rural population of India. The data is as follows:

\begin{tabular}{|l|l|}
\hline Year & $\begin{array}{l}\text { HFCE (in Rs. Per } \\
\text { annum) }\end{array}$ \\
\hline 2007 & 689872.00 \\
\hline 2008 & 717469.00 \\
\hline 2009 & 780669.00 \\
\hline 2010 & 957337.00 \\
\hline 2011 & 1112160.00 \\
\hline 2012 & 1132760.25 \\
\hline 2013 & 1150535.30 \\
\hline
\end{tabular}


Table2. Rural HFCE, India

\section{Telecom Subscriber Base:}

Here, we have collected the number of subscribers for all seven years explicitly for rural India. The data is as follows:

\begin{tabular}{|l|l|}
\hline Year & $\begin{array}{l}\text { Rural Subscriber Base } \\
\text { (in millions) }\end{array}$ \\
\hline 2007 & 45.70 \\
\hline 2008 & 73.92 \\
\hline 2009 & 22.21 \\
\hline
\end{tabular}

\begin{tabular}{|l|l|}
\hline 2010 & 200.81 \\
\hline 2011 & 282.23 \\
\hline 2012 & 330.82 \\
\hline 2013 & 349.21 \\
\hline
\end{tabular}

Table3. Rural Subscriber Base, India Analysing the pattern of Rural Literate Population, HFCE and Rural Subscriber Base over the years, as the base for both these data is same, we get the following graph:

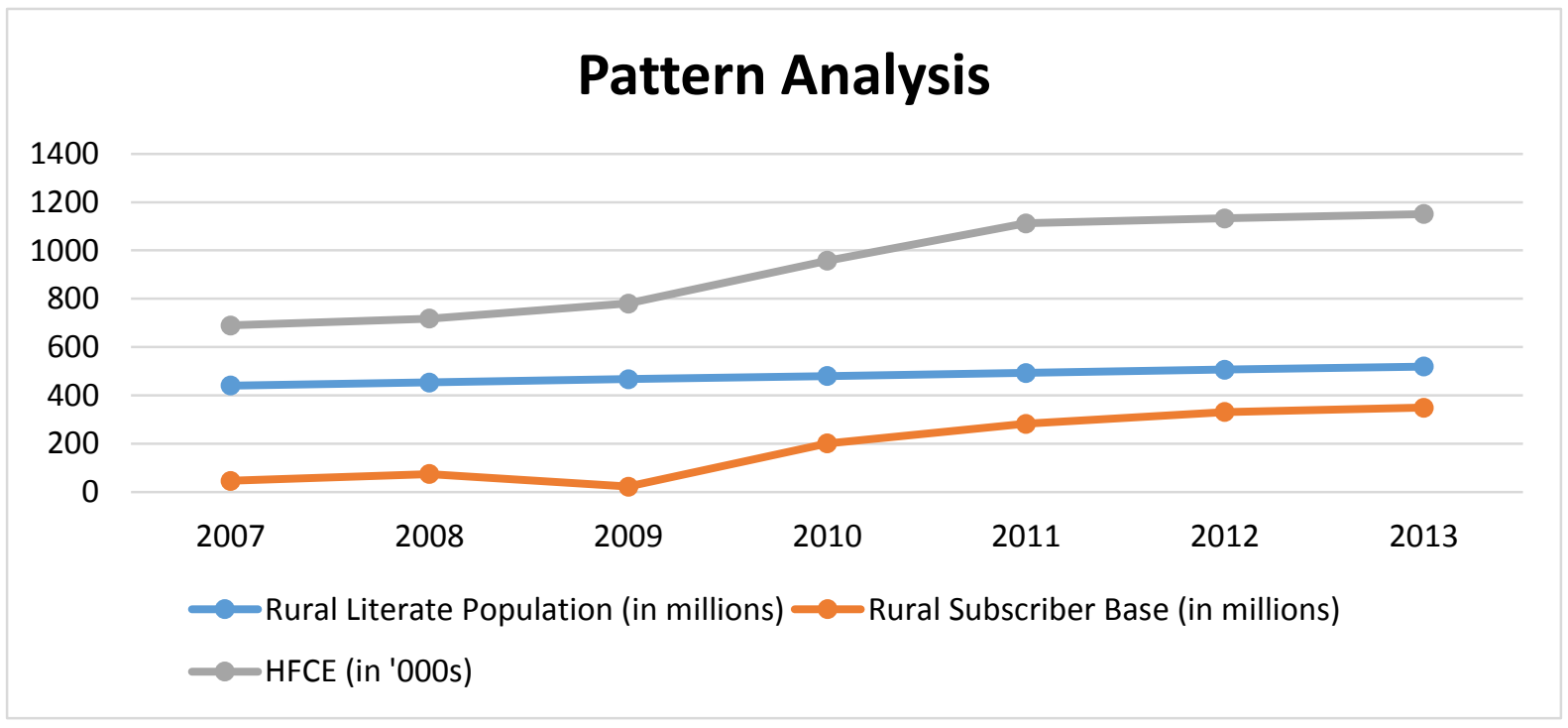

Fig 4: Comparative Analysis of the Three Parameters

Data Analysis Using SPSS:

To analyse the correlation between these variables, we have applied following tests, 
in SPSS, on the above mentioned data. The outputs of these are mentioned below:

1. Correlation Analysis

2. Regression Analysis

1. Correlation Analysis:
With the help of SPSS, we have found significant correlation between the three parameters. The result as well as analysis is written below:

a. Correlation between Rural Literate Population and HFCE:

Correlations

\begin{tabular}{|c|c|c|c|}
\hline & & Lit_No & HFCE \\
\hline \multirow[t]{3}{*}{ Lit_No } & Pearson Correlation & 1 & $.964^{\mathrm{N}}$ \\
\hline & Sig. (2-tailed) & & .000 \\
\hline & $N$ & 7 & 7 \\
\hline \multirow[t]{3}{*}{ HFCE } & Pearson Correlation & $964 \mathrm{~m}$ & 1 \\
\hline & Sig. (2-tailed) & .000 & \\
\hline & $N$ & 7 & 7 \\
\hline
\end{tabular}

Table 4. Correlation - HFCE and Rural Literate Population

Analysis:

Total sample size of Lit_No and HFCE considered for analysis is seven $(\mathrm{N}=7)$. Pearson correlation states degree of dependency among the variables. From the above table we can observe that Lit_No and HFCE are strongly positively correlated (correlation $=0.964)$ which means that increase or decrease in Lit_No will bring proportionate change in HFCE. Higher the educated number of people in rural sector higher is the household consumption expenditure.

b. Correlation between Rural Literate Population and Rural Subscriber Base: 
ELK

Asia Pacific Journals

$\underline{\text { www.elkjournals.com }}$

\section{Correlations}

\begin{tabular}{|ll|r|r|}
\hline & & Lit_No & RUral_Subs \\
\hline Lit_No & Pearson Correlation & 1 & .934 \\
& Sig. (2-tailed) & & .002 \\
& $\mathrm{~N}$ & 7 & 7 \\
\hline Rural_Subs & Pearson Correlation & .934 & 1 \\
& Sig. (2-tailed) & .002 & 7 \\
& $\mathrm{~N}$ & 7 & \\
\end{tabular}

**. Correlation is significant at the 0.01 level (2-tailed).

Table 5. Correlation - Rural Subscriber Base and Rural Literate Population

Analysis:

From the above table we can observe that Lit_No and Rural_Subs are strongly positively correlated $($ Correlation $=0.934) . \quad$ Variation in literacy number will bring proportionate change rural subscriber base and vice-aversa.

c. Correlation between Rural Subscriber Base and HFCE:

Correlations

\begin{tabular}{|ll|r|r|}
\hline & & RUral_Subs & \multicolumn{1}{c|}{ HFCE } \\
\hline RUral_Subs & Pearson Correlation & 1 & $.972^{\mathrm{m}}$ \\
& Sig. (2-tailed) & & .000 \\
& $\mathrm{~N}$ & 7 & 7 \\
\hline HFCE & Pearson Correlation & $.972^{\mathrm{x}}$ & 1 \\
& Sig. (2-tailed) & .000 & 7 \\
& $\mathrm{~N}$ & 7 & \\
& & & 7 \\
\end{tabular}

**. Correlation is significant at the 0.01 level (2-tailed).

Table 6. Correlation - Rural Subscriber Base and HFCE

Analysis:

From the above table we can observe that Rural_Subs and
HFCE are strongly positively correlated (Correlation $=0.972)$. Variation in Household 
ELK ASIA PACIFIC JOURNAL OF SOCIAL SCIENCES

ISSN 2394-9392 (Online); DOI: 10.16962/EAPJSS/issn.2394-9392/2014

Volume 1 Issue 2 (2015)

ELK

Asia Pacific Journals

$\underline{\text { www.elkjournals.com }}$

expenditure will bring
proportionate change rural
subscriber base and vice-a-
versa.

2. Regression Analysis:

With the help of SPSS, we have

done regression analysis of the three
Variables Entered/Removed ${ }^{\mathrm{a}}$

\begin{tabular}{|l|l|l|l|}
\hline Model & $\begin{array}{c}\text { Variables } \\
\text { Entered }\end{array}$ & $\begin{array}{c}\text { Variables } \\
\text { Removed }\end{array}$ & Method \\
\hline 1 & HFCE, Lit_No' & & Enter \\
\hline
\end{tabular}

a. Dependent Variable: RUral_Subs

b. All requested variables entered. parameters. We are able to form an equation, based on the result, of the rural subscriber base as a function of Rural Literate Population and HFCE. The result as well as analysis is written below:

\section{Model Summary}

\begin{tabular}{|l|c|r|r|r|}
\hline Model & R & R Square & $\begin{array}{c}\text { Adjusted R } \\
\text { Square }\end{array}$ & $\begin{array}{c}\text { Std. Error of } \\
\text { the Estimate }\end{array}$ \\
\hline 1 & $.972^{\mathrm{a}}$ & .945 & .918 & 39.78474 \\
\hline
\end{tabular}

a. Predictors: (Constant), HFCE, Lit_No

ANOVA $^{\mathrm{a}}$

\begin{tabular}{|ll|r|r|r|r|r|}
\hline \multicolumn{1}{|c|}{} & \multicolumn{1}{c|}{$\begin{array}{c}\text { Sum of } \\
\text { Model }\end{array}$} & \multicolumn{1}{c|}{ Squares } & df & Mean Square & F & Sig. \\
\hline 1 & Regression & 109830.564 & 2 & 54915.282 & 34.694 & $.003^{\text {b }}$ \\
& Residual & 6331.301 & 4 & 1582.825 & & \\
& Total & 116161.865 & 6 & & & \\
\hline
\end{tabular}

a. Dependent Variable: RUral_Subs

b. Predictors: (Constant), HFCE, Lit_No 
Table 7. Regression Analysis Output

Analysis:

- Seven values for HFCE and Lit_No are taken by SPSS by ENTER method which is a default method.

- Rural subscriber are strongly correlated to HFCE and Lit_No with $\mathrm{R}=0.972$. Change in either of HFCE and Lit_no (which are constants) will strongly affect Rural_Sub in proportionate manner.

- $\mathrm{R}$ square is coefficient of determination (For sample). It states how much variance in one variable is explained by other. From the above table we can state that variables are strongly correlated.

- Adjusted R square on other hand defines variance for population.

- F value explains how close data is from the regression line. It is a ratio of explained to unexplained variance. This value should be as large as possible.

- By means of beta value Line of regression can be plotted. It formulates an equation which gives relation between dependent and independent variable. Referring to table of coefficients, equation for line of regression will be-

Rural_Subs= $-349.079-$

0.049*Lit_No+1.010*HFCE

Data Analysis using Eviews:

To analyse the correlation between these variables, we have applied following tests on the above mentioned data. The outputs of these and its analysis is mentioned below:

1. Correlogram

2. Granger Causality Test

1. Correlogram: 
Asia Pacific Journals

www.elkjournals.com

\begin{tabular}{|c|c|c|c|c|c|c|}
\hline Autocorrelation & Partial Correlation & & $\mathrm{AC}$ & PAC & Q-Stat & Prob \\
\hline$\left.\right|^{* * * *} . \mid$ & $\left.\right|^{* * * *} . \mid$ & 1 & 0.504 & 0.504 & 2.8979 & 0.089 \\
\hline$\cdot 1^{*} \cdot 1$ & . $\quad$ | .1 & 2 & 0.119 & -0.181 & 3.0858 & 0.214 \\
\hline .1 .1 & .1 .1 & 3 & -0.056 & -0.049 & 3.1353 & 0.371 \\
\hline .1 .1 & $\cdot 1^{*} \cdot 1$ & 4 & 0.000 & 0.104 & 3.1353 & 0.535 \\
\hline .1 .1 & . ${ }^{\star}|-|$ & 5 & 0.000 & -0.066 & 3.1353 & 0.679 \\
\hline 1.1 & .1 .1 & 6 & 0.000 & 0.014 & 3.1353 & 0.792 \\
\hline
\end{tabular}

Augmented Dickey-Fuller Test Equation Dependent Variable: D(TR) Method: Least Squares

\begin{tabular}{lrlll}
\hline \hline \multicolumn{1}{c}{ Variable } & Coefficient & Std. Error & t-Statistic & Prob. \\
\hline \hline \multicolumn{1}{c}{ TR(-1) } & -0.123559 & 0.219514 & -0.562873 & 0.5978 \\
\multicolumn{1}{c}{ C } & 70.46737 & 49.74056 & 1.416698 & 0.2158 \\
\hline \hline R-squared & 0.059589 & Mean dependent var & 47.43429 \\
Adjusted R-squared & -0.128493 & S.D. dependent var & 70.42789 \\
S.E. of regression & 74.81593 & Akaike info criterion & 11.70290 \\
Sum squared resid & 27987.12 & Schwarz criterion & 11.68744 \\
Log likelihood & -38.96013 & F-statistic & 0.316826 \\
Durbin-Watson stat & 2.246889 & Prob(F-statistic) & 0.597823 \\
\hline \hline
\end{tabular}

Table 8. Correlogram Test - Output

2. Granger Causality Test:

Analysis:

Least square method is used for correlogram analysis. It specifies an equation comprising of all the parameters who would affect the data.

\section{CONCLUSION AND SUGGESTIONS:}

The entire test brings up a conjoint conclusion that all the parametersEducation, Agriculture and Technology are strongly correlated to 
each other. Deviation, positive or negative in any one of these factors will bring sequential changes in other factors as well.

By means of Socio-Economic model propose above, telecom operators can focus on vital parameters to foster rural penetration. They can work in alliance with the government to launch new schemes or enrich existing ones to give and get maximum benefit to/from citizens. The technological growth in the rural sector of India can be brought about with increase in tele density and more usage of telecom services. The support to a farmer is a must for his growth and education. Once he is educated he can make positive use of the mobile services and increase his agro- business network as well. The growth of telecom technology is possible through educating the agricultural sector and providing them basic services on regular basis. Technological growth can be more fructified with education and can enhance the overall productivity of the sector and of the nation.

\section{LIMITATIONS}

Following are the limitations of this research project:

- The data on which the analysis is based is secondary data. Though from reliable sources like websites TRAI, RBI, etc., the dependency of this research is solely on secondary data.

- Due to lack of region-specific data on rural literate population and HFCE, the study cannot be narrowed down and region-specific analysis and model could not be proposed.

- Only three parameters (i.e. two socio-economic parameters - HFCE and rural literate population; and rural subscriber base) have been considered to adhere to the scope.

\section{REFERENCES}

[1] Department of Telecommunications, Ministry of Communications and Information Technology, Annual 
Report (2012-13). Website: http://www.dot.gov.in/sites/default/file s/Telecom\%20Annual\%20Report2012-

13\%20(English)\%20_For\%20web\%20 (1).pdf

[2] Department of Electronics and Information Technology. Website: http://deity.gov.in/

[3] Department of Telecommunications. Website: http://www.dot.gov.in/

[4] Planning Commission of India. Website: http://12thplan.gov.in

[5] Twelfth Five Year Plan (2012-2017). Economic Sectors, Volume II. Website:

http://planningcommission.gov.in/plan s/planrel/12thplan/pdf/12fyp_vol2.pdf

[6] Stakeholders conference On pilot project scheme for access to ICTs \& ICT enabled services for persons with disabilities, September 7, 2011

[7] Department of Agriculture and Cooperation, Ministry of Agriculture. Website: www.agricoop.nic.in

[8] Indian Council of Agricultural Research. Website: www.icar.org.in

[9] India: The Impact of Mobile Phones, The Policy Paper Series Number 9, January 2009. Website: http://www.enlightenmenteconomics.c om/Reports/assets/indiaimpact.pdf

[10] Kumar Saha (Sep 11 2014). Role Of ICT in E-Governance and Rural Development.

Website: http://www.cxotoday.com/story/roleof-ict-in-e-governance-and-ruraldevelopment

[11] http://yojana.gov.in/cms/(S(m2mzef5 5ipvmrc45ehppdef4))/pdf/Kurukshetra \%5CEnglish\%5C20 12/January.pdf

[12] Food and Agriculture Organisation of the United Nations. Website: http://www.fao.org/fileadmin/template s/tci/pdf/Investment_Days_2010_2nd_ day/Session_I/MobileTelephon y-PBMarch09-EN.pdf

[13] Poverty in India, Wikipedia. Website: http://en.wikipedia.org/wiki/Poverty_i n_India

[14] Arathi Chitla(July-Aug 2012). Impact of Information and Communication Technology on Rural India, IOSR Journal of Computer Engineering (IOSRJCE), ISSN: 22780661 Volume 3, Issue 2 (July-Aug. 2012), PP 32-35. Website: http://www.iosrjournals.org/iosrjce/papers/Vol3-issue2/F0323235.pdf

[15] http://www.capacity.org/capacity/ope ncms/en/topics/gender-and-socialinclusion/icts-and-empowermentofindian-women.html

[16] T.T. Sreekumar (2007). Cyber kiosks and dilemmas of social inclusion in rural India, Sage Journals. Website: http://mcs.sagepub.com/content/29/6/ 869.short 
[17] http://125.19.12.220/applications/Brih aspat.nsf/6dca49b7264f71ce65256a81 003ad1cb/82f2c15ccd4dd9a065 256b37001af3fe/\$FILE/it_fai.pdf

[18] Chitra B.M (Nov 2012). ICT Initiatives in Indian Agriculture, newsletter of the International Federation for Information Processing (IFIP) Working Group 9.4 titled Social Implications of Computers in Developing Countries, IIM Ahmedabad, Volume 22, No. 3, November 2012. Website: http://www.iimahd.ernet.in/egov/ifip/ nov2012/chitra.htm

[19] http://www.csiindia.org/c/document_library/get_file ?uuid=1f810ed9-6c9b-41ab-8ffa4 fe4f449ced5\&groupId=10157

[20] Claire J. Glendenning, \& Pier Paolo Ficarelli (2012). The Relevance of Content in ICT Initiatives in Indian Agriculture, IFPRI Discussion Paper 01180.

Website: http://www.ifpri.org/sites/default/files /publications/ifpridp01180.pdf

[21] Reading Material, Training programme on Supply Chain Management in Agriculture, National Institute of Agricultural Extension Management. Website: http://www.manage.gov.in/studymater $\mathrm{ial} / \mathrm{scm}-\mathrm{E} . \mathrm{pdf}$

[22] Soham Sen, \& Vikas Choudhary. ICT Applications for Smallholder
Inclusion in Agribusiness Supply Chains. Website: http://www.ictinagriculture.org/sites/i ctinagriculture.org/files/final_Module 10.pdf

[23] Broken link in the agricultural supply chain. Website: http://www.livemint.com/Opinion/Vp m7RO8SnhkpCtC8QWPwSN/Broken -link-in-the-agriculturalsupplychain.html

[24] Sazzad Parwez (2014). Supply chain dynamics of Indian agriculture: reference to information technology and knowledge management Stewart Postharvest Review 2014, ISSN: 1745-9656. Website: http://www.stewartpostharvest.com/V ol10_2014/April_2014/Parwez.pdf

[25] http://nrlp.iwmi.org/PDocs/DReports/ Phase_01/04.\%20WTO\%20and\%20a griculture $\% 20$ \%20RPS\%20Malik.pdf

[26] Matopolous A, Vlachopoulou M, Manthou V and Manos B. A conceptual framework for supply chain collaboration: empirical evidence from agribusiness food industry. Supply Chain management: An International Journal 2007: 12 (3): $177-186$.

[27] Keynote address delivered by Shri Harun R. Khan, Deputy Governor, Reserve Bank of India, at the 16th 
ELK ASIA PACIFIC JOURNAL OF SOCIAL SCIENCES

ISSN 2394-9392 (Online); DOI: 10.16962/EAPJSS/issn.2394-9392/2014

Volume 1 Issue 2 (2015)

ELK

Asia Pacific Journals

$\underline{\text { www.elkjournals.com }}$

Conference of Globoil India held in Mumbai on September 22, 2012

[28] Shri Harun R. Khan (2012). Keynote Address, Food Inflation and Agricultural Supply Chain Management, Reserve Bank of India. Website:
http://www.rbi.org.in/scripts/BS_Spee chesView.aspx? $\mathrm{Id}=736$

[29] Household Final Consumption Expenditure, The World Bank. Website:

http://data.worldbank.org/indicator/N E.CON.PRVT.CD 